\title{
Recurrent Adenovirus Infection
}

National Cancer Institute

\section{Source}

National Cancer Institute. Recurrent Adenovirus Infection. NCI Thesaurus. Code C156254.

An adenovirus infection that has recurred after a period of remission. 